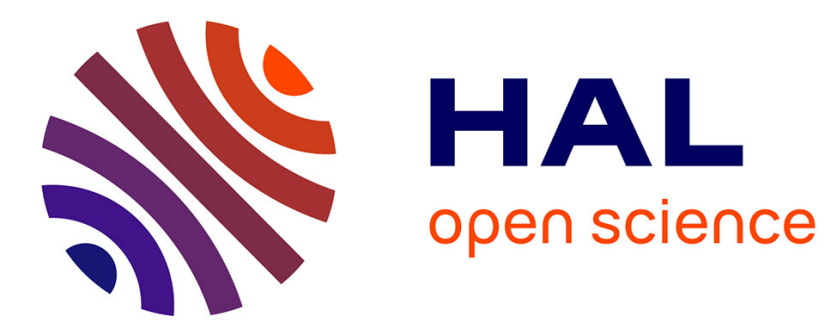

\title{
The Scope and the Subtleties of the Contextualism/Literalism/Relativism Debate
}

Isidora Stojanovic

\section{To cite this version:}

Isidora Stojanovic. The Scope and the Subtleties of the Contextualism/Literalism/Relativism Debate. Language and Linguistics Compass, 2008, 2 (6), pp.1171-1188. 10.1111/j.1749-818x.2008.00086.x . ijn_00326140

\section{HAL Id: ijn_00326140 \\ https://hal.science/ijn_00326140}

Submitted on 1 Oct 2008

HAL is a multi-disciplinary open access archive for the deposit and dissemination of scientific research documents, whether they are published or not. The documents may come from teaching and research institutions in France or abroad, or from public or private research centers.
L'archive ouverte pluridisciplinaire HAL, est destinée au dépôt et à la diffusion de documents scientifiques de niveau recherche, publiés ou non, émanant des établissements d'enseignement et de recherche français ou étrangers, des laboratoires publics ou privés. 


\title{
The Scope and the Subtleties of the
}

\section{Contextualism / Literalism / Relativism Debate}

\author{
Isidora Stojanovic \\ Institut Jean Nicod - CNRS - ENS - EHESS \\ (forthcoming in Language and Linguistics Compass)
}

\section{$\underline{\text { abstract }}$}

In recent years, a number of new trends have seen light at the intersection of semantics and philosophy of language. They are meant to address puzzles raised by the context-sensitivity of a variety of natural language constructions, such as knowledge ascriptions, belief reports, epistemic modals, indicative conditionals, quantifier phrases, gradable adjectives, temporal constructions, vague predicates, moral predicates, predicates of personal taste, etc. A diversity of labels have consequently emerged, such as 'contextualism', 'indexicalism', 'invariantism', 'literalism', 'minimalism', 'relativism', variously qualified. The goal of this essay is to pinpoint the issues that lie at the heart of the recent debates, clarify what is at stake, and provide a snapshot of the current theoretical landscape. 


\section{Literalism vs. contextualism}

Though it is customary to talk of the contextualism/literalism debate, or of the contextualism/relativism debate, the use of the definite article is misleading in both cases, since there appears to be a family of debates, on different fronts, that seem to fit these labels equally well. We will see, for example, that a position that counts as "relativist" in the light of one debate may well count as "contextualist" from the point of view of another debate. Throughout the paper, I will be striving to disentangle the terminological web that covers the field and threatens to blur the issues under discussion. For the sake of simplicity, I will describe the differences among the various positions in relation to a specific topic, that of quantifier domain restriction. Even though domain-dependence has not been of major interest to relativism, the choice is methodological, since the parameters at stake are easy to isolate, and the range of possible positions fairly easy to delineate. In this section, I will discuss the contextualism/literalism debate. Once the different contextualist positions have become more clear, the goal of Section 2 will be to disentangle those from the recently emerged relativist positions. Section 3 offers a broad survey of the range of topics that have been the concern of the debates, with references to the literature.

Suppose that at a symposium on semantics, the following dialogue takes place between Josh and Marsha:

(1) Josh: Are there any philosophers? 
(2) Marsha: Yes, though most people are linguists.

According to the literalist, what Josh (literally) asked in (1) is whether there are any philosophers tout court, and Marsha's answer in (2) is made true by the mere existence of some philosopher somewhere, regardless of how things stand at the symposium. And while her answer to Josh's question is almost trivially true, what she further says is almost trivially false, since, according to the literalist, it means that most people in the universe are linguists. In other words, literalism holds that quantifier words such as 'there are', 'most', 'every', etc. always behave the way we would take them to behave in e.g. "There are no unicorns" or "Most people have an IQ over 80"; that is, that they quantify over everything. Minimalism is, so to speak, literalism generalized: it holds that the only cases in which context can have an impact on truth value are those of resolving lexical and syntactic ambiguities and of determining the reference of indexical pronouns such as 'I', 'this', or 'today'.

Contextualism (broadly understood) is the view that Marsha's answer in (2) isn't made true by the mere existence of some philosopher somewhere, but only by there being some philosophers in the domain relevant in the context in which the sentence is uttered and/or evaluated for truth. In our case, it would typically be the domain consisting of the people attending the symposium. Similarly, for her sentence in (2) to be true, it is only required that most people in the contextually restricted domain are linguists.

The literalism/contextualism debate directly concerns semantics, in the sense that there is no agreement on what the truth values of given sentences 
(in given contexts) are. In a situation in which $90 \%$ of the people at the symposium are linguists, the literalist predicts that what Marsha says in (2) is false, while the contextualist predicts that it is true. The data gathered in the literature on quantifiers appear to show that ordinary speakers' intuitions on truth value are more in line with the contextualist predictions than with the literalist. Literalism thus faces the problem of explaining away the accuracy of ordinary speakers' intuitions, and its proponents typically argue that what speakers' intuitions actually track is some level of pragmatically conveyed content, rather than semantic content itself. ${ }^{1}$

While contextualism is the mainstream view with respect to quantifier domain restriction, there remains considerable disagreement on the issue of how context is involved in determining the truth values of sentences containing quantifiers. The first branching point is on the question of whether there is something either in the meaning or in the syntax of the expressions used that calls for domain restriction, the alternative being that the context somehow in and by itself restricts the domain of quantification. Hence:

(a) mainstream contextualism: there is some lexical, syntactic or semantic level at which the contextual restriction over the domain of quantification is represented.

(b) radical contextualism: there is nothing, at any linguistic level, that calls for domain restriction - rather, it is the result of optional or "free" pragmatic

1 In other words, literalists hold that speakers often mistake what is conveyed for what is said (on this distinction, see Grice 1989). For a critical discussion of the role of speakers' intuitions for semantics, see e.g. (Bach 1994). 
processes. $^{2}$

It is important to realize that the position in (a) actually stands for a whole family of positions. The differences primarily concern the level at which the contextual restriction is taken care of, but even when this is agreed upon, there may still be even more subtle divergences among the various authors. What follows is a rough survey of the most easily identifiable positions:

(i) syntactic ellipsis: there is a mismatch between the phonological and the syntactic form; e.g. the sentence in (1) is really "Are there at this symposium any philosophers?" and in (2), "Most people at this sympositm are linguists."

(ii) implicit arguments with domain variables: the logical form of (2) is something like: [Most $\mathrm{x}$ : Human $\mathrm{x} \& \mathrm{x} \in \mathrm{Y}$ ](Linguist $\mathrm{x}$ ), where $\mathrm{Y}$ is a variable that takes as its values sets of things (individuals, objects or events). Thus in (2), the value that it would take is something like the domain of things that are relevantly related to the symposium.

2 The "mainstream" vs. "radical" terminology is mine. I have deliberately avoided using the "moderate" vs. "radical" terminology, since it is used differently by different authors. For instance, for (Recanati 2004), both moderate and radical contextualism would fall under option (b): the difference is that his "moderate" contextualist does not deny that sentences may have a compositionally determined "literal" meaning, obtained from the conventional meanings of the words in the sentence and from its syntax, while his "radical" contextualist holds that the notion of literal meaning is difficult to even make sense of. What I am calling "mainstream contextualism" comes closest to what (Recanati 2004) calls "indexicalism". On the other hand, (Cappelen and Lepore 2005) distinguish "moderate" from "radical" contextualism depending on how many expressions are taken to depend on the context. For them, one is a contextualist as soon as one allows some contextdependence over and above that of some basic set of context-dependent expressions (such as indexical pronouns), and one becomes a "radical" contextualist by arriving at the view that all expressions in the language depend on the context in one way or another. Thus their way of distinguishing two forms of contextualism turns out to be orthogonal to the line drawn between (a) and (b). 
(iii) implicit arguments with predicate variables: the logical form of (2) is something like: [Most $\mathrm{x}$ : Human $\mathrm{x} \& \mathrm{Px}]($ Linguist $\mathrm{x})$, where $\mathrm{P}$ is a secondorder variable that takes as its values predicates. Thus in (2), it would presumably take something like the complex predicate 'attending the symposium'.

(iv) implicit arguments without variables: the lexical semantics of the quantifier phrase itself requires an argument, presumably a domain over which the quantifier ranges. There are no hidden variables in the logical form; rather, a contextually restricted domain is provided directly at the stage of semantic interpretation. ${ }^{3}$

(v) parameters in the point of evaluation: the output of semantic interpretation is something that will return a truth value only with respect to a point of evaluation, and part of what the latter specifies (other than the time and world of evaluation), are the domains over which the quantifiers range. Thus neither the syntactic nor the semantic representation of (2) depend on the context, but the truth value may still vary, depending on whether (2) is evaluated with respect to the symposium, or to some other situation or group of people, or to the entire universe.

The positions in (ii) and (iii) probably represent the dominant approach to quantifier domain restriction: see e.g. (Westerståhl 1985), (Stanley and

3 This sort of position may be attributed e.g. to (Jacobson 1999). 
Williamson 1995), (Stanley and Szabó 2000), or (Peters and Westerståhl 2006).

We will shortly see that (v) may be seen as a form of relativism, since it allows that the same sentence, with respect to the same context of utterance, may take different truth values, so long as it is evaluated with respect to different points of evaluation. A particular version of the position in (v) would be to say that the point that determines the truth value of a sentence (with respect to a context of utterance) is that point which corresponds to the context of utterance. We will shortly return to this issue, but what matters at this stage is that the differences among (i)-(v) are not, properly speaking, semantic differences. For, all these positions largely agree on the truth values that a sentence containing a quantifier phrase ought to be assigned (with respect to a given context). The differences among these frameworks reside in the ways in which truth value is derived from the meaning and the syntax of the sentence, certain facts about the context, and possibly other parameters.

To sum up, the central difference between literalist and contextualist approaches, at least in how they handle quantifier phrases, is that they provide different predictions of truth value. Literalism, and minimalism in particular, systematically predict truth values that fail to conform to speakers' intuitions, having thus to argue that conformity to intuitions is not a criterion for semantic content. On the other hand, there is agreement, among the different forms of contextualism, that the success of a theory should be tested by its ability to account for the data, which are obtained by canvassing for speakers' intuitions. But there is also (internal) disagreement, on the question of how precisely to account for those data, hence disagreement on various 
aspects internal to the semantic machinery, or related to its interface with syntax and with the lexicon.

\section{The Emergence of relativism}

Before addressing the differences among the various relativist positions in relation to quantifier domain restriction, let me try to give you a sense of the intuition underlying relativism in relation to time. Consider the following claim:

(3) Tokyo is the capital of Japan.

While (3) is true, one might ask whether it has always been true. And, given that in the past, Kyoto used to be the capital of Japan, it does not seem incorrect to say the claim made in (3), though true now, was not always true in the past. The intuition that the truth value of (3) may vary with time is what relativism with respect to time, or temporalism, tries to capture.

Now, it is important to keep clear the distinction between temporalism and the uncontroversial idea that the truth value of (3) may depend on time. Of course, a sentence such as "Josh is sitting" may be true if uttered while Josh is sitting, and false if uttered while he is standing. What temporalism insists on is not that the sentence in (3), if uttered at different times, may be assigned different truth values. Rather, it is that the sentence in (3) as uttered in 2008 expresses something that is now true, but used to be false. 
The difference between the two ways in which truth value depends on times, viz. relativity vs. mere context-dependency, is quite clear in the case of future contingents. Suppose that I say the following on Tuesday:

(4) It will rain tomorrow.

Suppose that it does rain on Wednesday, but not on Thursday. Intuitively, (4) is neither true nor false on Tuesday, given that the course of future events is still indeterminate at that point, but once it becomes settled that it would rain on Wednesday, (4) becomes true. Thus we ought to be able to evaluate (4) with respect to Wednesday - but note that when we do so, the time with respect to which we interpret the indexical 'tomorrow' is Tuesday and not Wednesday (otherwise (4) would end up being false).

Examples that involve future contingents show that the sensitivity of truth value to time cannot be reduced to context-sensitivity. This further sensitivity to time is not incompatible, though, with contextualist semantics. While the time of the context of utterance is relevant to determining the semantic values of temporal indexicals like 'tomorrow', the time of the context of assessment is relevant to determining the truth value of the utterance as a whole. ${ }^{4}$

This relativist move is applicable, albeit not as immediately as in the case of time, to domains of quantification. Reconsider the example from Section 1, and suppose that the following is said while talking about the symposium:

4 It must be stressed that one can adopt a relativist solution to future contingents without subscribing to temporalism in general, that is, without accepting that the truth value of present-tensed claims such as (3) may vary with time. Such a view, arguably defended in (MacFarlane 2002), would apply the same treatment to (unembedded) tense as to (overt) temporal indexicals. For an alternative, non-relativist approach to future contingents, see e.g. (Bonomi and Del Prete 2008). 
(5) Most people are linguists.

Intuitively, (5) is true. However, one might ask whether it remains true in some larger situation, such as the one whose domain includes not only the linguists' symposium, but, say, all the symposia currently held at a certain convention center. And one could well hold that what (5) expresses, though true in the "small" situation where almost everyone is a linguist, is false with respect to the larger situation where linguists are a minority. ${ }^{5}$ The idea is, then, that not only the truth value of the sentence in (5) depends on a domain of quantification, but even when the sentence is used in a particular context, that which it expresses still varies in truth value across different domains. There are several ways in which this idea may be fleshed out. Note, however, that the proposed classification may reveal an idiosyncratic perspective on the issue, and is not generally agreed upon. ${ }^{6}$

(I) standard relativism: the output of semantic interpretation is a function from points of evaluation to truth values, but the point of evaluation specifies not only a possible world and a time, but also a domain of quantification.

5 This sort of suggestion may be found, for instance, in (Barwise and Perry 1983) and (Barwise 1989); see also (Recanati 1997).

6 As of now, there is no classification generally agreed upon, and the issue of which proposal defends which form of relativism, or of how the various forms of relativism differ from one another and depart from the various versions of contextualism, has been the topic of several recent papers (see e.g. (López de Sa 2007), just to mention one). 
(II) assessment-relativism: the truth value of a sentence is a function not only of a context that settles the interpretation of indexicals, called context of utterance, and of a point of evaluation, but also of another context, called context of assessment (which may but need not coincide with the context of utterance).

(III) metaphysical relativism: the output of semantic interpretation is a function from points of evaluation to truth values, and the points of evaluation are merely possible worlds, but the facts themselves that determine the values of that function are relative, rather than absolute.

To see to what amounts the position that I call "metaphysical relativism", often believed to be relativism par excellence, reconsider (3). The idea would be that the semantic interpretation of that sentence gives us a certain proposition, namely, that Tokyo is the capital of Japan, and this proposition can be thought of as a function $f$ that, if you give it a possible world as input, returns a truth value as output. Take $\mathrm{w}_{\mathrm{A}}$ to be the actual world. Metaphysical relativism would thus hold that the value of $f\left(\mathrm{w}_{\mathrm{A}}\right)$ is True, but there were times in the past when the value of $f\left(\mathrm{w}_{\mathrm{A}}\right)$ was False (namely, while Kyoto was the capital of Japan). ${ }^{7}$

Now, from the point of view of set theory, a one-place function that, given

7 A form of relativism of a similar sort is arguably defended in (MacFarlane 2008), even if at other places, he holds a position closer to assessment-relativism (indeed, the terminology of contexts of assessment comes from his work). 
an argument, returns value True, just cannot be the same function as one that, given the same argument, returns False. The only way to make sense of the idea that a function semantically associated with a sentence returns different truth values given one and the same argument, is that it is a two-place rather than a one-place function, and that the difference in truth value results from the difference in the second argument. But this would make metaphysical relativism collapse into standard relativism, and a metaphysical relativist would presumably insist that part of her point is precisely the rejection of the standard set-theoretic approach.

It is for similar reasons that I find it problematic to describe the disagreement between contextualists and relativists as disagreement on the issue of whether the truth of propositions is relativized. For, the notion of proposition is primarily a theoretical artifact, used in describing and modeling a variety of phenomena, and it has become customary to reserve the term 'proposition' for the kind of item that returns a truth value when evaluated at a possible world, and to use a qualified or different term for the similar kind of item that returns a truth value when evaluated at a possible world and some other parameter(s) - e.g. 'temporal proposition' when it requires a time parameter, or, more generally, 'propositional function'. To describe relativism as the view that the truth of propositions is relativized (to times, domains, or whatever else) would, then, seem to turn it into a proposal about terminology, rather than about any substantial issue.

Turning now to the position that I am calling "standard relativism", note that it has already been listed in Section 1 as a "contextualist" position. 
Indeed, the difference between standard contextualism, which typically uses implicit arguments for elements on which the truth value turns out to depend (such as domains of quantification), and standard relativism, which, instead of using implicit arguments, makes room for such elements in the point of evaluation, is perhaps an interesting difference from the point of view of the syntax-semantics interface, but much less so from the point of view of semantics alone. The output of "contextualist" semantic interpretation, when evaluated with respect to an assignment of values to implicit arguments, will normally return the same truth value as the output of "relativist" semantic interpretation, when applied to a point of evaluation whose parameters are assigned the same values as those that were assigned to the corresponding implicit arguments in the former case. ${ }^{8}$

Now, positions such as standard relativism are sometimes "accused" of being contextualist for a different and, I believe, not entirely justified reason, a discussion of which will reveal another way of distinguishing relativism from contextualism. Following (Kaplan 1989), it is widely accepted that in languages containing indexicals, the truth value of a sentence depends on two things: a first parameter, usually called context, which is responsible for the interpretation of indexicals, and a second parameter, a point of evaluation, which consists at least of a possible world parameter, but may contain other parameters, such as a time parameter, a standards-of-precision parameter, as in (Lewis 1980), and why not a domain-of-quantification parameter. ${ }^{9}$ This

8 The equivalence is shown e.g. in (Stojanovic 2008), but the technical results on which it relies have been long known from model-theory of modal logics; see e.g. (Kuhn 1980).

9 Following (Kaplan 1989) and (Lewis 1980), it is often assumed that contexts and points of evaluation are differently structured, and that contexts involve an agent parameter, 
assumption, widely shared by contemporary semantic theories, reveals something like a triadic conception of truth:

$\underline{\text { standard relativist conception of truth: }}$ truth $_{3}$ is a property of a sentence $S$, with respect to a context $C$, relative to a point of evaluation $\mathrm{E}$.

In other words, truth is less of a property and more of a three-place relation among sentences, contexts, and points of evaluation.

Now, it may be tempting to try reducing truth to what it appears to be at face value, namely a property. The first step is to arrive at a dyadic conception of truth:

standard reductionist conception of truth: truth $_{2}$ is a property of a sentence $S$, with respect to a context $C$, which obtains if and only if truth $_{3}$ obtains of $S$, with respect to $C$, and relative to the point of evaluation $E_{C}$ that consists of the corresponding features of context $C$.

Finally, rather than assigning truth value to sentences in contexts, one might want to talk of utterances being true simpliciter, thereby arriving at monadic truth:

responsible for interpreting the indexical ' $\mathrm{I}$ ', while points of evaluation don't. But, as Kaplan himself recognized (Kaplan 1989: $511 \mathrm{fn}$ ), there is some arbitrariness in deciding what to count as "aspects of contexts" and what to count as "features of cirumstances" (i.e. of points of evaluation). I should also mention that the two parameters are called differently by different authors: in (Kaplan 1989), it is "context" and "circumstance", in (Lewis 1980), it is "context" and "index", in (Predelli 2005), it is "index" and "point of evaluation", etc. 
utterance-contextualist conception of truth: truth $_{1}$ is a property of an

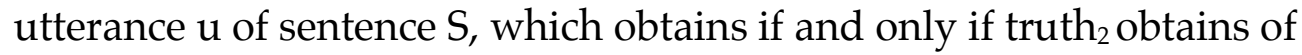
$\mathrm{S}$ with respect to the context of utterance $\mathrm{u}$.

I am not sure whether it makes much sense to ask which, if any, among these conceptions is the right one. Arguably, truth ${ }_{3}$ is indispensable, because that is the notion deployed in compositional semantics. It may be suggested that truth $_{1}$ is at least useful, because ordinary speakers intuitions on truth are typically elicited by presenting speakers with particular utterances, rather than theoretical artifacts of the form (sentence, context, point of evaluation). But what about truth 2 ? It has been held that truth ${ }_{2}$ is the notion of truth required for logic. In particular, (Kaplan 1989: 547) defines logical validity in terms of it: "[Formula] $\varphi$ is valid (...) iff for every structure $U$, and every context $c$ of $\mathrm{U}, \varphi$ is true in $c$ (in $\mathrm{U}$ )." However, the idea that the Kaplanian conception of validity is the right one seems to me just as questionable as the idea that, say, truth 2 , rather than $\operatorname{truth}_{1}$ or truth $_{3}$, is the right conception of truth. In particular, one can also hold that $\varphi$ is valid iff for every structure $U$, every context $c$ of $\mathrm{U}$, and every point of evaluation $e$ of $\mathrm{U}, \varphi$ is true in $c$ at $e$ (in $\mathrm{U}) .^{10}$

Turning back to the distinction among the different forms of relativism proposed in the beginning of this section, reconsider the view that handles quantifier domain restriction by positing a domain parameter in the point of

10 Kaplan himself acknowledged the possible definition of validity based on truth-of-asentence-in-a-context-at-a-point-of-evaluation, and called it "neotraditional" (Kaplan 1989: 549). For a discussion of the two notions of validity, see e.g. (Predelli and Stojanovic 2008). 
evaluation (listed under (I) or, equivalently, under (v) in Section 1). The mere presence of a domain parameter in the point of evaluation does not warrant that such a view will count as relativist. Indeed, "contextualism" is sometimes understood as applying to views that embody either a monadic or a dyadic conception of truth. Hence if standard relativism is paired with the assumption that the domain of evaluation that determines truth value must be the same as the domain of the context, the resulting position will provide the same predictions of truth value as any of the contextualist positions (i) to (iv) from Section 1. In turn, the issue of whether to classify such a position under "contextualism" or under "relativism" is pretty much up for grabs. ${ }^{11}$

Let me end this section with a brief discussion of some motivations behind assessment-relativism. As noted earlier, the dependence of truth value on some parameter, such as the time parameter, cannot always be reduced to the phenomenon of context-dependence known from the study of indexicality. In particular, it is widely held that the time relevant to interpreting temporal indexicals like 'today' or 'tomorrow', but also tense, is contributed by the context of utterance. However, sentences that report contingent future events arguably lack a truth value when evaluated at the time of utterance, and only start having one when evaluated at some future time at which the course of events has been settled. It can thus be said that the truth of such sentences depends not only on the context of utterance, but also on what came to be called a context of assessment. Although this kind of motivation is peculiar to

11 (MacFarlane 2007) has dubbed that sort of position "non-indexical contextualism." What is important to see, though, is that what would justify the label "contextualism" is not so much the failure to relativize truth to something like a context of assessment, but rather, the underlying reductionist conception of truth. 
future contingents, assessment-relativism has been proposed as a solution to a variety of other issues, and motivated with a variety of other considerations. For reasons of space, I shall only mention one. It has to do with the idea that an assessment-sensitive sentence and its negation express a contradiction even when they are assessed from different contexts and can be therefore both true. Epistemic modals are the case at point: if I tell you that it might be raining outside, and you tell me that it can't be raining, we are contradicting each other, even if my evidence allows for the possibility that it is raining (hence what I say is true with respect to my own context of assessment), while you have conclusive evidence that it is not raining outside (hence what you say is true with respect to your own context of assessment). Assessment-sensitive expressions thus contrast with indexicals: said by different speakers, "I am sitting. - No, I am not sitting" is simply an infelicitous exchange. More importantly, they also contrast with expressions that one might want to handle by adding an appropriate parameter in the point of evaluation. Reconsider domain restriction. While one may be happy with the idea that the sentence "Most people are linguists" as used in a given context may still receive different truth values if evaluated at different domains, it is also clear that if I tell you that sentence while speaking about the linguists' symposium, and you reply “No, most people aren't linguists" while talking about something else (say, your department, or some other symposium), then, even if at face value we seem to be contradicting each other, our apparent disagreement clearly rests upon a misunderstanding. ${ }^{12}$

12 It is probably for this reason that assessment-relativism has, to my knowledge, not been defeneded in the case of quantifier domain restriction. 


\section{The Scope of the debate}

My primary goal has been not only to explain how contextualism departs from literalism, and how relativism departs from contextualism, but also to point out some subtle differences among positions that may be said to belong to one and the same camp. What I want to do in this last section is briefly go over a number of topics that have been the concern of the debate, and provide some references. It goes without saying that different types of expressions may need different treatments, hence one should not expect there to be a view that will apply to all the cases equally well.

\section{Knowledge ascriptions}

Epistemology is an area for which contextualism has been of particular importance. Traditionally, the verb 'know' was not considered to be contextsensitive, so the received view was literalism - or, to use the preferred term, invariantism. Invariantist views disagree nevertheless on the necessary and sufficient truth conditions for ascriptions of the form ' $S$ knows that $p$ '. Skeptical invariantism proposes such stringent conditions that virtually every knowledge ascription comes out false, while moderate (insensitive) invariantism proposes conditions in the spirit of the "justified true belief" analysis of knowledge. Epistemic contextualism arose as a response to this debate, trying to reconcile the intuitions behind both views by suggesting that the truth conditions of knowledge ascriptions depend on the epistemic standards at 
play in the context in which the ascription is made. In response to contextualism, a new form of invariantism arose: subject-sensitive, or interestrelative, invariantism, which holds that knowledge ascriptions, while insensitive to the context, are sensitive to the goals and interests of the subject to whom knowledge is ascribed. Another reaction to contextualism was relativism, which holds that the truth value of a knowledge ascription does not depend, or, at least, does not only depend on the context of ascription and the subject's interests, but (also) on the context from which the ascription is being evaluated, or assessed, for its truth value. Since the literature on this topic is very vast, the proposed references will be easily found wanting, but nevertheless: for skeptical invariantism, see (Unger 1979); for moderate insensitive invariantism, see (Williamson 2000, 2005); for subject-sensitive invariantism, see (Hawthorne 2004) and (Stanley 2005); for contextualism, see (DeRose 1992), (Lewis 1996), (Rysiew 2001), (Kompa 2003), (Lawlor 2005), (Blome-Tillmann 2006), and articles in (Preyer and Peter (ed.) 2005:12-130), covering both sides of the debate; for relativism, see (MacFarlane 2005); for the specific case of self-ascriptions of knowledge, see (Bonnay and Egré 2008).

\section{Belief reports}

Consider the sentence "Josh believes that Gordon Sumner is a great singer" and suppose that Josh believes indeed of that person that he is a great singer, but only knows him under his stage name 'Sting'. Then it is customary to say that on its de re reading, the sentence is true, while on its de dicto reading, it is false. Although the problem was brought up more than a century ago in 
(Frege 1892), the debate still goes on as to whether there is indeed such an ambiguity, and how it should be handled. Literalism denies the ambiguity (or, at least, its relevance to semantics), recognizing only the de re reading; see (Salmon 1986), (Soames 1987), and more recently (Taylor 2007). Contextualist manoeuvres include taking the 'that'-clause itself to be context-sensitive in more or less the same way in which demonstrative pronouns are (Richard 1993), taking the verb 'believe' to involve an implicit argument for the mode of presentation in which the content of belief is believed by the believer (Crimmins and Perry 1989), allowing free pragmatic processes in the interpretation of belief reports (Recanati 1993), and so on. In (Predelli 2005: 161-183), a version of what I have described as standard relativism is applied to the problem of belief reports.

\section{Epistemic modals and indicative conditionals}

Sentences like "Josh might be in the garage" and "If he isn't in the garage, he's in the basement" appear to depend for their truth value not only on how things are in the world (viz. on where Josh actually is), but also on the available information. ${ }^{13}$ Contextualists hold that the information relevant to truth value is the contextually available information: either that to which the speaker herself has access, or that available to some larger group. ${ }^{14}$ On the other hand, relativists hold that the truth value may vary depending on the

13 Partly because of this, but also because of their peculiar syntactic behavior, (Edgington 1995) and (Bennett 2003) hold that indicative conditionals are simply not truth-evaluable.

14 The two proposals correspond to the distinction between "solipsistic" and "nonsolipsistic" contextualism in terms of (MacFarlane 2006). 
information available to the person who evaluates the modal or the conditional for its truth value. For instance, "Josh might be in the garage" would be true from the point of view of the speaker while being false from the point of view of a better informed person who has just seen him in the basement. For contextualist treatments of indicative conditionals, see e.g. (Bradley 2002) and (Stalnaker 2005), and of epistemic modals, e.g. (von Fintel and Gillies 2008). For relativist treatments of epistemic modals, see e.g. (Egan et al. 2005), (MacFarlane 2006) or (Stephenson 2007).

\section{Time and tense}

Although temporalism has its origin in presocratic philosophy, with Stoics and Megarians, its logical and semantic foundations should be traced to (Prior 1957), following whose work most semantic frameworks, including (Kaplan 1989) and (Lewis 1980), include a time parameter in the point of evaluation. As noted earlier, the mere presence of this parameter does not necessarily give rise to a relativist framework - thus e.g. the framework in (Kaplan 1989), in which the preferred notion of truth is the dyadic truth-in-acontext (as opposed to the triadic truth-in-a-context-at-a-point-of-evaluation), is typically classified as contextualist. For criticisms of temporalism, see e.g. (Evans 1985) and more recently (King 2003); for defense, see e.g. (Dummett 1997), (Recanati 2007: 53-86). For a relativist treatment of time slightly different from standard temporalism, see (MacFarlane 2002, 2008). 


\section{Location}

It is widely agreed that sentences such as 'It is raining', rather than being true or false simpliciter, take a truth value depending on the context, and, in particular, on some contextually salient location. ${ }^{15}$ What is not yet agreed upon is how this location-dependence comes about. According to (Stanley 2000), it is due to an implicit argument, handled at the level of syntax. (Taylor 2007) holds that the location argument comes directly from the lexical meaning of 'rain', rather than from syntax. For (Recanati 2004), reference to the location of rain is due to an optional pragmatic process of free enrichment. Note that, as in the case of time, it is not uncommon to include, as in (Lewis 1980), a location parameter in the point of evaluation. (Predelli 2004) applies a version of standard relativism to location, arguing that the variations in truth value of "It is raining" are due to its being evaluated at different points of evaluation. More concerned with cognitive issues, (Perry 1986) suggests that in certain cases, as when the agent lacks any representation of locationdependence, the thought that it is raining concerns a particular location without yet representing it. The location, in turn, determines the truth value of the thought, hence if the location changes, the truth value may change, too; however, the content of the thought will remain the same.

\section{Gradable adjectives and vagueness}

The problem raised by gradable adjectives is to explain how the truth value of a sentence such as "Josh is tall" may depend on some relevant comparison

15 (Cappelen and Lepore 2007) go literalist even for this case and hold, against any common sense, that "It is raining" is true or false independently of any context or point of evaluation. 
class - e.g. it may be true with respect to his colleagues at work, false with respect to his basketball team. Contextualism is the dominant approach to gradable adjectives; see e.g. (Kamp 1975), (Ludlow 1989), or (Kennedy and McNally 2005). Literalism, i.e. the view that whether an individual is tall may be settled independently of any context, is defended in (Cappelen and Lepore 2005), while (Richard 2004) opts for some sort of relativism.

There is a tight connection between gradable adjectives and vague predicates, although vagueness concerns a broader class of expressions, and is even believed by some to arise with any kind of linguistic construction. For contextualist solutions to problems of vagueness (including the Sorites paradoxes), see e.g. (Lewis 1979), (Bosch 1983), (Kamp and Partee 1995), (van Deemter 1995), (Raffman 1996), (Fara 2000), (Shapiro 2006), and (Kennedy 2007). ${ }^{16}$

\section{Predicates of color}

As pointed out in Section 1, the term 'contextualism' sometimes refers to the more marginal view on which in general, syntax, meaning, and semantically constrained reference are altogether insufficient to determine truth conditions. Imagine a situation in which the naturally red leaves of a Japanese maple tree have been painted in green, and suppose that, pointing to them, Josh says:

(6) These leaves are green.

Contextualism holds that, despite of understanding the meaning of all the

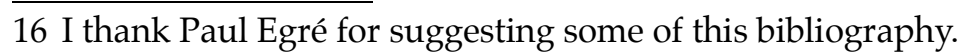


words in (6) and of having identified the leaves referred to, context is still needed in order to determine truth value. For, if uttered in a context in which what is at stake is the observable color of leaves, (6) is true, but if uttered in a context in which it is their natural color that matters, (6) seems false. This "radical" form of contextualism is defended e.g. in (Searle 1980), (Travis 1996) and to some extent in (Recanati 2004). Literalism holds that the only contextsensitivity in (6) is that of the demonstrative and of the present tense - which still leaves room for several options:

(i) insisting that there is a privileged sense of 'green' (e.g. the color of the observable surface), so that (6) only has the first, true reading.

(ii) taking ' $x$ is green' to be true if $x$ is green in some way or another (so that (6) will again only have a true reading).

(iii)acknowledging that there can be both a true and a false utterance of (6), but insisting that they are utterances of sentences with different meanings, the one involving 'green ${ }_{1}$ 'which would mean something like 'green on observable surface', and the other, the homonym 'green ${ }_{2}$, which would mean something like 'naturally green'. ${ }^{17}$

Let me also mention two other contextualist proposals: (Szabó 2001), which treats predicates of color as involving an implicit argument and thus being subject to the same kind of contextualist treatment as other indexicals, and (Rothschild and Segal 2008), which treats them as indexical predicates. Finally,

17 For instance, Kennedy and McNally (2008) appeal to considerations regarding the gradability of 'green' to argue that predicates of color give rise to systematic ambiguity. 
the proposal in (Predelli 2005b), which could qualify as "relativist", is that if we keep the referent of 'these leaves' fixed, the sentence will have a stable semantic content, which is a function from points of evaluation to truth values, but different contexts may determine different points of evaluation, and, thereby, different truth values. For example, if (6) is evaluated in situation in which what matters is the surface color of the leaves, it will be true, but if it is evaluated in a situation in which their natural color matters, it will be false.

It is worth emphasizing that for radical contextualists, color predicates are just one instance of what they take to be a general phenomenon, namely, that there is no way of determining meaning and truth conditions independently of context. It is also worth noting that Predelli's strategy, which roughly consists in handling the contextual variations of truth value at a postcompositional or, if you prefer, post-semantic stage, is also applicable across the board.

\section{Moral predicates and predicates of personal taste}

Ethical relativism, i.e. the idea that what is morally right in one community need not be so in another community, is a long standing position in moral philosophy (see e.g. Harman 1975), and can be applied to the semantics of predicates like 'right' or 'wrong' and of deontic expressions like 'ought'. For a contextualist take on moral predicates, see e.g. (Brogaard 2007).

Predicates of taste like 'delicious' are easily amenable to a relativist treatment, the idea being that what is delicious for me need not be delicious 
for you: de gustibus non est disputandum. Note that in the moral case, the relevant parameter of relativization is typically a community, while in the case of taste, it can be, and often is, an individual. Relativist semantics for predicates of personal taste is defended e.g. in (Kölbel 2002), (Lasersohn 2005) or (Richard 2008). The proposal in (Stephenson 2007) combines relativism (since there is a "judge" parameter in the point of evaluation) with contextualism (since there is a silent nominal item $\mathrm{PRO}_{\mathrm{j}}$ that picks out the judge of evaluation). (Stojanovic 2008) argues that (standard) relativism and (mainstream) contextualism not only yield the same predictions of truth value, but are also on a par when trying to account for disagreement on matters of taste. (Glanzberg 2007) defends a contextualist position, integrated with a contextualist account of gradable adjectives.

\section{Bibliographic references}

Bach, Kent. 1994. Seemingly semantic Intuitions. Meaning and Truth. ed. by John Campbell et al. New York: Seven Bridges Press. 21-33.

Barwise, Jon. 1989. The Situation in logic. Stanford: CSLI Publications.

—— and John Perry. 1983. Situations and attitudes. Cambridge, Mass.: MIT Press.

Bennett, Jonathan. 2003. A Philosophical guide to conditionals. Oxford: Oxford UP.

Blome-Tillmann, Michael. 2006. The Indexicality of 'knowledge'. Philosophical Studies. (online first) 
Bradley, Richard. 2002. Indicative conditionals. Erkenntnis 56. 345-378.

Brogaard, Berit. 2007. Moral contextualism and moral relativism. The Philosophical Quarterly. (online first.)

Bonnay, Denis and Paul Egré. 2008. Margins for error in context. Relative Truth. ed. by Max Kölbel and Manuel García-Carpintero. Oxford: Oxford UP.

Bonomi, Andrea and Fabio Del Prete. 2008. Evaluating future-tensed sentences in changing contexts. ms.

Bosch, Peter. 1983. "Vagueness" is context-dependence. A Solution to the sorites paradox. Approaching vagueness. ed. by Thomas Ballmer and Manfred Pinkal. Amsterdam: North Holland. 189-210.

Cappelen, Herman and Ernie Lepore. 2005. Insensitive semantics. Oxford: Blackwell.

— and _ 2007. The Myth of unarticulated constituents. Situating semantics: essays on the philosophy of John Perry. ed. by Michael O'Rourke and Corey Washington. Cambridge: MIT Press. 199-214. Crimmins, Mark and John Perry. 1989. The Prince and the phone booth: reporting puzzling beliefs. The Journal of Philosophy 86. 685-711. van Deemter, Kees. 1995. The Sorites fallacy and the context-dependence of vague predicates. Quantifiers, deduction, and context. ed. by Makoto Kanazawa, Christopher Piñon and Henriëtte de Swart. Stanford: CSLI Publications. 59-86.

DeRose, Keith. 1992. Contextualism and knowledge attributions. Philosophy and Phenomenological Research 52. 913-929. 
Dummett, Michael. 1997. Existence, possibility, and time. Analyomen 2/1, ed. by Georg Meggle. Berlin: De Gruyter. 43-67

Edgington, Dorothy. 1995. On conditionals. Mind 104. 235-329.

Egan, Andy, John Hawthorne and Brian Weatherson. 2005. Epistemic modals in context. in Preyer and Peter. 131-168.

Evans, Gareth. 1985. Does Tense Logic Rest Upon a Mistake? Collected Papers. Oxford: Clarendon Press. 343-363.

Fara, Delia Graff. 2000. Shifting sands: an interest-relative theory of vagueness. Philosophical Topics 28. 45-81.

von Fintel, Kai and Thony Gillies. 2008. CIA leaks. Philosophical Review 117.77-98.

Frege, Gottlob. 1892. Uber Sinn und Bedeutung. Zeitschrift für Philosophie und philosoophiche Kritik 100. 25-50. English translation: On Sinn and Bedeutung. The Frege Reader, ed. by Michael Beaney. Oxford: Blackwell Publishers, 1997. 151-171.

Glanzberg, Michael. 2007. Context, content, and relativism. Philosophical Studies 132. 1-16.

Grice, Paul. 1989. Studies in the way of words. Cambridge, Mass.: Harvard University Press.

Harman,Gilbert. 1975. Moral relativism defended. The Philosophical Review 84. 3-23.

Hawthorne, John. 2004. Knowledge and lotteries. Oxford: Oxford University Press

Jacobson, Pauline. 1999. Towards a variable-free semantics. Linguistics and 
Philosophy 22. 117-184.

Kamp, Hans.1975. Two theories about adjectives. Semantics for Natural Language, ed. by Edward Keenan. Cambridge: Cambridge University Press.

— and Barbara Partee. 1995. Prototype theory and compositionality. Cognition 57. 129-191.

Kaplan, David. 1989. Demonstratives: an essay on the semantics, logic, metaphysics, and epistemology of demonstratives and other indexicals. Themes from Kaplan, ed. by Joseph Almog, John Perry and Howard Wettstein. Oxford University Press. 481-563.

Kennedy, Christopher 2007. Vagueness and grammar: the semantics of relative and absolute gradable adjectives. Linguistics and Philosophy 30. 1-45.

_ and Louise McNally. 2005. Scale structure, degree modification, and the semantics of gradable predicates. Language 81. 345-381.

— and - 2008. Color, context and compositionality. ms.

King, Jeffrey. 2003. Tense, modality, and semantic values. Philosophical Perspectives 17. 195-246.

Kölbel, Max. 2002. Truth without objectivity, Routledge.

Kompa, Nikola. 2003. The Context sensitivity of knowledge ascriptions. Grazer Philosophische Studien 64, 1-18.

Kuhn, Steven T. 1980. Quantifiers as modal operators. Studia Logica 39. 145158.

Lasersohn, Peter. 2005. Context dependence, disagreement, and predicates of personal taste. Linguistics and Philosophy 28. 643-686. 
Lawlor, Krista. 2005. Enough is enough: pretense and invariance in the semantics of 'knows that'. Philosophical Perspectives, 19. 211-236.

Lewis, David. 1979. Score-keeping in a language game. Semantics from different points of view, ed. by Rainier Bäuerle, Urs Egli and Arnim von Stechow. Berlin: Springer. 172-185.

— 1980. Index, context and content. Philosophy and grammar, ed. by Stig Kanger and Sven Ohman. Dordrecht: Reidel. 78-100.

— 1996. Elusive Knowledge. Australasian Journal of Philosophy 74. 549 567.

López de Sa, Dan. 2007. The Many relativisms and the question of disagreement. International Journal of Philosophical Studies 15. 269-279. Ludlow, Peter. 1989. Implicit comparison classes. Linguistics and Philosophy 12. 519-533.

MacFarlane, John. 2002. Future contingents and relative truth. The Philosophical Quarterly 53. 321-336.

— 2005. The Assessment sensitivity of knowledge attributions. Oxford Studies in Epistemology 1, ed. by Tamar Szabó Gendler and John Hawthorne. Oxford: Oxford University Press. 197-233.

_ 2006. Epistemic modals are assessment sensitive. UC Berkeley, ms.

— 2007. Nonindexical contextualism. Synthese (online first)

— 2008. Truth in the garden of forking paths. Relative truth, ed. by Max

Kölbel and Manuel García-Carpintero. Oxford: Oxford UP.

Perry, John. 1986. Thought without representation. Supplementary

Proceedings of the Aristotelian Society 60. 137-152. 
Peters, Stanley and Dag Westerståhl. 2006. Quantifiers in Language and Logic. Oxford: Clarendon Press.

Predelli, Stefano. 2004. The Lean mean semantic machine. The Semantics / pragmatics distinction, ed. by Claudia Bianchi. Stanford: CSLI Publications.

-2005. Contexts: meaning, truth, and the use of language. Oxford: Clarendon Press.

_ 2005b. Painted leaves, context, and semantic analysis. Linguistics and Philosophy 28. 351-374.

_ and Isidora Stojanovic. 2008. Semantic relativism and the logic of indexicals. Relative truth. ed. by Max Kölbel and Manuel GarcíaCarpintero. Oxford: Oxford University Press.

Preyer, Gerhard and Georg Peter (eds.) 2005. Contextualism in philosophy. Oxford: Oxford University Press.

Prior, Arthur. 1957. Time and modality. Oxford: Oxford University Press.

Raffman, Diana. 1996. Vagueness and context-relativity. Philosophical Studies 81. 175-92.

Recanati, Francois. 1997. Domains of discourse. Linguistics and Philosophy 19. 445-475.

— 1993. Direct reference: from language to thought. Oxford: Blackwells.

_ 2004. Literal meaning. Cambridge: Cambridge University Press.

_ 2007. Perspectival thought: a plea for moderate relativism. Oxford: Oxford University Press.

Richard, Mark. 1993. Attitudes in context. Linguistics and Philosophy 16. 123- 
148.

_ 2004. Contextualism and relativism. Philosophical Studies. 119. 215-242.

— 2008. When truth gives out. Oxford: Oxford University Press.

Rothschild, Daniel and Gabriel Segal. 2008. Indexical Predicates. Forthcoming in Mind and Language.

Rysiew, Patrick. 2001. The Context-sensitivity of knowledge attributions. Noûs 35. $477-514$.

Salmon, Nathan. 1986. Frege's puzzle. Cambridge, Mass.: MIT Press.

Searle, John. 1980. The Background of meaning. Speech-act theory and Pragmatics, ed. by John Searle et al. Dordrecht: Reidel. 221-232.

Shapiro, Stuart. 2006. Vagueness in context. Oxford: Oxford University Press.

Soames, Scott. 1987. Direct reference, propositional attitudes, and semantic content. Philosophical Topics 15. 47-87.

Stalnaker, Robert. 2005. Conditional propositions and conditional assertions. New work on modality, ed. by J. Gajewski, V. Hacquard, B. Nickel, and S. Yalcin. MIT Working Papers in Linguistics 51. 207-31.

Stanley, Jason. 2000. Context and logical form. Linguistics and Philosophy 23. 391-434.

_ 2004. On the linguistic basis for contextualism. Philosophical Studies 119. 119-146.

— 2005. Knowledge and practical interests. Oxford: Oxford University Press.

— and Zoltan Szabó. 2000. On quantifier domain restriction. Mind and Language 15. 219-261. 
_ and Timothy Williamson. 1995. Quantifiers and context-dependence. Analysis 55. 291-295.

Stephenson, Tamina. 2007. Judge dependence, epistemic modals, and predicates of personal taste. Linguistics and Philosophy 30: 487-525.

Stojanovic, Isidora. 2008. Talking about taste: disagreement, implicit arguments, and relative truth. Forthcoming in Linguistics and Philosophy.

Szabó, Zoltan. 2001. Adjectives in context. Perspectives on semantics, pragmatics, and discourse, ed. By Robert Harnish and I. Kenesei. Amsterdam: John Benjamins. 119-46.

Taylor, Kenneth A. 2007. Misplaced modification and the illusion of opacity. Situating semantics: essays on the philosophy of John Perry. ed. by Michael O’Rourke and Corey Washington. Cambridge: MIT Press. 215250.

Travis, Charles. 1996. Meaning's role in truth. Mind 105. 451-466.

Unger; Peter. 1979. Ignorance: a case for skepticism. Oxford: Oxford University Press.

Westerståhl, Dag. 1985. Determiners and context sets. Generalized quantifiers in natural language, ed. by Johan van Benthem and Alice ter Meulen. Dordrecht: Foris. 45-71.

Williamson, Timothy. 2000. Knowledge and its limits. Oxford: Oxford UP. _ 2005. Contextualism, subject-sensitive invariantism and knowledge of knowledge. Philosophical Quaterly 55. 213-235. 